NOTAS

\title{
LA CEGUERA INCONCLUSA: LO TRÁGICO AL FINAL DE LA HISTORIA
}

Eduardo Milán*

A Mariano Molina

Son los hombres de antes, que pertenecían a otra esfera de la existencia que no es la nuestra...

\section{Jean-Pierre Vernant}

$\mathbf{L}$ de lo trágico o de tragedia, en relación a los fundamentos griegos, es la desaparición de un mundo, la no existencia de lo que existía como verdadero o como original. Lo trágico hoy en día es la falta de un telón de fondo que evocar, la carencia de apoyatura mítica que resulta de un corte en la historia: del mismo modo que los griegos actualizaban sus mitos, los modernos actualizábamos (por superación, es cierto) nuestra historia. El "fin de la historia" (Fukuyama) suspende la posibilidad trágica en el aire; $\sin$ escenario y sin subsuelo se

* Departamento Académico de Estudios Generales, ITAM. suspende el concepto que deriva directamente de una existencia y no de una actualización de un trasfondo. Las posibilidades, entonces, serían pocas; o remitirse, al margen o al costado o por encima de la historia, a aquellos mitos fundadores (si consideráramos, en una postura esencialista, al hombre como el mismo, más allá de la historia) o aceptar un partir de cero que es el partir de este fantasmal "fin de la historia". Sería muy parecido a la visión de Hegel, para quien la historia se convertiría a sí misma en tragedia, en el conjunto de su pasado y de su futuro, en su memoria y en su estar.

Con ese acoplamiento se anula como devenir. Ya no hay posibilidades 
NOTAS

de avance porque toca al fin, también, el proceso de secularización, de pérdida por parte del hombre de todo lo que lo ligaba al origen. Paradójicamente, cuando el hombre ya no tiene nada más que perder se acaba, trágicamente, la historia; como si la historia se sostuviera a condición de un superávit todavía existente, un plus que perder. Esa lectura negativa se sostendría, a su vez, en la convicción de que el progreso se impulsa con base en una cantidad de pérdida posible o con base en un mundo que está ahí para ser perdido. Tácticamente no parece haber sido otra cosa, pero en lugar de la historia ahora se instala el hecho trágico de haber perdido la historia, hilo conductor del vínculo del hombre con el pasado. Volviendo a la cita de Vernant que encabeza este texto, si podemos hablar todavía de tragedia en relación a autores más recientes de la cultura (Sha-

92 kespeare, Cervantes, Racien) es por el desplazamiento histórico que permite que estas obras arraiguen en el marco trágico antiguo, en la primitiva maqueta trágica. Habría que interpretar este concepto de Vernant como que el desplazamiento se produce desde un presente hacia un pasado y no viceversa. El pasado es imán del presente, pero cl presente no puede ser imán del pasado. Hablaríamos de trans-historicidad retroactiva. ¿Dónde queda entonces la posibilidad prospectiva de lo trágico, su aquí y su ahora? La tragedia, según los griegos, es una actualización del pasado, un "make it new", un aquí y ahora que sucede, más allá de sus fines aleccionadores o morales, para no perder el contacto con sus mitos y leyendas. La tragedia ahora, el pasaje de la obra de arte (el género) a la obra de vida (la existencia) es la articulación de una ruptura, de una pérdida de memoria en relación al pasado: un desencadenamiento, en el sentido en que los eslabones de la cadena se separan, una dispersión. Lo que para los griegos es una condensación actualizante, un objeto (he ahí el género, la forma) para nosotros es una diseminación, una individuación (he ahí el de-generamiento, la antiforma de lo trágico para nosotros). Eso explicaría una de las características de los héroes trágicos de la ficción contemporánea; no tienen pasado, no están "fundados" (Kafka, Beckett, Musil). En otras palabras, no tienen historia: el "fin de la historia" rubrica una carencia anterior que subyacía debajo de la máscara que prometía un final feliz. Un pequeño recorrido temporal es útil para entender una posibilidad.

Edipo quiere saber. Para los griegos saber es saber el futuro. En eso consiste la sabiduría, que para los griegos es siempre oracular, adivinatoria, hasta el siglo $\mathrm{V}$ a.C. Después del siglo $\mathrm{V}$, si el paradigma es la sabiduría, comenzaría la traducción; comenzaría la filosofía que es el inicio de la posibilidad de saber después del final del saber, el conocimiento cuando acaba la sabiduría. Platón, que es la gran bisagra (para utilizar un término caro a Foucault), es el gran consciente de que ya todo terminó; siempre remite a un antes, a un logos anterior, a un habia una vez. Lo perdido se convierte en 
NOTAS

ideal, lo mistérico en idea y en el intento por parte del hombre de traducir el mito, de volverlo real una y otra vez. Si bien es cierto, como dice Eliot, que el hombre no soporta demasiada realidad, también es cierto que el hombre no soporta demasiado la ausencia de lo real, aunque sea como idea, más allá de lo concreto. Comienza el intento humano por desvelar (desvelar aquí es traducir, pasar de un lenguaje oscuro, secreto, a un lenguaje claro, accesible), por hacer patente o por hacer presencia todo lo que en un principio lo era pero ahora es ausencia. Platón es el depósito de la sabiduría pero no la sabiduría; Platón no pretende sustituir la condición mistérica de la sabiduría. De ahí que tienda a convertir en huella, en ideal lo que le fue dado, en un mundo de abstracciones que la filosofía, secular a partir de la pérdida de la sabiduría, ha identificado con lo que es espíritu o cabe dentro de su dominio. La "metafísica de la presencia" toma forma debido a aquella nostalgia y nos acusa, por un gesto indirecto de Heidegger, del "olvido del ser".

Pero Edipo quiere saber y saber para los griegos es saber el futuro. ¿Por qué quiere saber el futuro? ¿Por qué quiere la sabiduría si sabe como griego que la sabiduría es un secreto reservado para pocos? En un sentido lato la sabiduría para los griegos, la voluntad de saber, es el principio de la transgresión. El oráculo está disponible pero no trata a todos por igual. Y Edipo es el consultor más inteligente, un desvelador de enigmas y acertijos. ¿Qué es lo que pregunta cuando inte- rroga al oráculo acerca de sus verdaderos padres? Pregunta por su origen. Pero no hay pregunta, en el sentido mítico, en el sentido del héroe, en el sentido de Edipo, por el origen de uno: hay pregunta por el origen. El oráculo, que no puede contestar sobre el Origen con mayúscula contesta literal y metafóricamente sobre el final de Edipo: "Matarás a tu padre y te casarás con tu madre". La respuesta es: "acabarás con tu origen". Esa es la lección oracular que recibe Edipo por preguntar por el origen en un contexto en que lo real evoca en un presente continuo, está continuamente evocando, a toda la estructura mítica. No hay que olvidar aquí que la tragedia, aunque tenga apoyatura épica en el nivel de sus personajes, integrantes del plantel mitológico del pueblo, tiene acción catártica a nivel simbólico con un basamento literal determinante. Es un juego que se juega doblemente; en el nivel simbólico y en el nivel real con igual intensidad. Edipo es mito y rey, mito y hombre, simbólico y real, sagrado y profano. Edipo es doble. Edipo quiere saber el origen y no quiere saber el origen. El oráculo es claro: si quieres obtener el origen obtendrás el final. Rompe así la dualidad de Edipo.

La hybris de la modernidad es la misma: querer saber. Vehiculizar el conocimiento a través de la historia, a la ciencia a través de la historia es conseguir un camouflage (la historia del hombre es la historia del camouflage de los orígenes) que permita ignorar o volver oblicuo el hecho de que saber es perderse. Y que siempre com- 
NOTAS

porta una imposibilidad. La tragedia alecciona: su finalidad es moral. No se engaña, el Coro de Edipo rey es preciso: "La vida es una locura. Y tratar de terminar con esa locura es la ruina". El Coro defiende a la vida como caos, como un caos para el cual el intento de poner orden equivale a acabar con la vida misma. El Coro es negativo si el conocimiento es positivo. Pero, además, hay una integración ahí: el hombre forma parte de la locura, una parte íntima. Querer saber es salirse de la locura, pero también, quedarse afuera (es la "afueridad". de Blanchot, la afueridad que condiciona la única posibilidad de sabiduría para el poeta), y también tomar conciencia del mecanismo, del cómo es. Arrancarse los ojos; eso es querer saber. Querer saber lleva a la imposibilidad de ver. Y volvemos al principio; saber es lo contrario de ver porque ver es ver el origen, lo que no se puede saber, lo que ahora es el lado velado. $\mathrm{Y}$ precisamente porque no se puede ver volvemos a la tragedia, a la imposibilidad de saber que impulsa la transgresión. Pero antes ya está la síntesis; hay tragedia porque no se puede ver. Lo trágico siempre es territorio de la luna.

La modernidad crea la ciencia sostenida en la evolución de discurso histórico para escapar a una verdad; el origen no sabido. La ciencia entra en la realidad por el Caballo de Troya de la historia, sólo que ese Caballo de Troya está vacío, no incluye más que su apariencia. No es la verdad sino un animal de madera. La fuerza del caballo era mítica y se perdió en el tiempo. Ahora es madera con forma de caballo. Pero esa ciencia pretendió ocupar, por lo menos, la misma posición de la filosofía después del apagón de la sabiduría en el siglo $\mathrm{V}$ a.C. La modernidad patentó la verdad primero en los hechos, luego en los discursos sobre los hechos. Quiso sustituir el vacío original por el lleno permanente del conocimiento, un conocimiento conseguido a como diera lugar. Pero en el siglo XIX el conocimiento se precipita hacia el abismo (con la visión trágica de Hegel: la tragedia triste y con la visión trágica de Nietszche: la tragedia alegre) y se arrastra y nos arrastra hasta hoy. ¿Qué ocurrió? El hombre no pudo superar el vacío al cual, en una carrera vertiginosa hacia el futuro, quiso olvidar por medio de la sustitución por un final feliz. La modernidad es el intento serio, despiadado, implacable y también lúcido de lucidez luciferina, de negar que la sabiduría acabó antes y que lo inaprehensible, por no poder cosificarlo, en un "esto es" que pueda simular, por una vez al menos, un "esto era que todavía es". En otras palabras, ha sido una lucha desesperada por escapar de la tragedia-sin origen para caer en una tragedia-con final; este espectral "fin de la historia". Con el quite de la historia del camino, la tragedia Squeda en situación expectante. Porque es la historia la que ocupaba, con su motor progresista ( $y$ con la ciencia positiva-dueña de la verdad) el lugar, justamente, del oráculo; es ella la que contestaba todas las preguntas, las que se podían hacer y las que no se podían hacer; para la historia no había 
diferencia. El hombre pierde también la capacidad de actualización del pasado (de ser pasado) en ese oráculo histórico: la pregunta es por el futuro (la sabiduría) pero lo que contesta (porque es donde la sabiduría habita) es el pasado. Ocurre entonces una metatragedia, el desplazamiento del eje de la historia (que en su perspectiva evolutiva permitía en forma emergente, aquí y allí, la aparición de "momentos" trágicos) al eje del individuo, quien recibe el impacto de una carencia: la carencia referencial oracular. No sólo está aislado con su "¿por qué?", sino que también está aislado con su "¿a quién?" La tragedia contemporánea consiste en una ausencia; no hay quién, nada ni nadie contesta. No hay sujeto.

Si no se olvida la lección de la tragedia griega, que consiste básicamente en alertar a los hombres acerca del peligro de cualquier transgresión, podemos plantear la pregunta: ¿Por qué, cuando no hay quien conteste, se redobla la necesidad de preguntar? ¿Por qué, luego, la necesidad de inventar quién responda? Y para sintetizar: ¿Qué es lo que queremos saber? Una posible respuesta a estas interrogantes es la que dice que todo final se vuelve necesario, útil, porque ocupa la posición del origen. Con la seguridad de un final (las teleologías cristianas o marxistas) sustituimos el origen; la certeza del final, certeza de la muerte y promesa de la resurrección, anula la incertidumbre del origen porque se coloca en el mismo nivel de desconocimiento; no importa de donde venimos porque tampoco sabemos a dónde va- mos, qué es a dónde vamos, qué hay y qué no hay adonde vamos. La aceptación de la certidumbre del final (condición de todateleología) es la aceptación de la incertidumbre del origen. La sustitución adquiere fuerza si comprobamos que la condición finalista, desde el punto de vista del conocimiento, eonlleva la abolición de toda metafísica (no sólo el señalamiento por el "olvido del ser"' sino también la permanente pregunta por el origen). La seguridad de un final resta tensión a todo principio, conocido o no. ¿Qué ocurre entonces cuando se amputa el final, en la perspectiva de Fukuyama, cuando se nos quita la posibilidad de un fin que cumpla, míticamente, el sueño de presenciar el momento en que la humanidad, el devenir humano se dobla sobre sí mismo y principio y fin se acoplan, se sustituyen y desaparecen? Quedamos nuevamente en posición de tragedia en vez de anularla o absorberla (exactamente: como la filosofía frente a la sabiduría), sin poder conocer el final. Sobreviene entonces el espanto, el horror de estar entre, de estar en medio $d e$, espacio que, paradójicamente para la mirada antimetafísica de Deleuze es donde lo importante ocurre, el espacio de la permanencia. Pero no es la permanencia feliz de Deleuze; es la permanencia espantosa que tiene el rostro de lo inmodificable, de la imposibilidad del cambio.

La tragedia actual se articularía no en la transgresión que significa cambio, alteración, revolución, manifestaciones en apariencia imposibles ahora. Se articularía, sí, en la imposibilidad 
NOTAS

de transgresión, en la obligación de aceptar un orden por más inhumano que pueda parecer. El individuo ya no es perseguido como el héroe trágico: es excluido de un orden. Entonces adquiere sentido la denominación anterior de metatragedia: es la imposibilidad, guiada por la falta de historia, de la tragedia para el ser humano. Porque al haber historia hay todavía eco: el discurso histórico, para el pensamiento trágico, había venido ocupando el lugar del discurso mítico. El diálogo operaba. La historia respondía persiguiendo, acosando, regulando y prometiendo. Ahora no hay respuesta. El orden ya no quiere aleccionar ni siquiera por capricho como en la mitología griega: requiere seguimiento, silencio, aceptación. Ya no estamos frente al dispositivo disparado por el héroe en Ediporey; estamos con Edipo solo, viejo, en Colono, sostenido a la

96 izquierda por un bastón de madera y a la derecha por la mano de su hija Antígona. Y, por si fuera poco, ciego. 